\title{
LA CRISIS DE LA CONSTITUCIÓN \\ EN EL PROCESO DE INTEGRACIÓN EUROPEA
}

\author{
JAVIER TAJADURA TEJADA \\ Profesor Titular de Derecho Constitucional \\ Universidad del País Vasco
}




\section{SUMARIO}

I. INTRODUCCIÓN. II. EL PRINCIPIO DEMOCRÁTICO COMO FUNDAMENTO DEL CONSTITUCIONALISMO CONTEMPORÁNEO. III. LA DIFERENTE EVOLUCIÓN DEL CONSTITUCIONALISMO EUROPEO: LIBERALISMO DOCTRINARIO Y NEGACIÓN DEL ESTADO CONSTITUCIONAL. IV. SUPREMACIA CONSTITUCIONAL, DERECHO INTERNACIONAL Y DERECHO COMUNITARIO. V. LA CRISIS DEL PRINCIPIO DE SUPREMACIA CONSTITUCIONAL DESDE UNA PERSPECTIVA FORMAL: LA APORÍA TEÓRICA ENTRE LAS PRETENSIONES DE SUPREMACIA DE LOS ORDENAMIENTOS CONSTITUCIONALY COMUNITARIO. VI. LA CRISIS DEL PRINCIPIO DE SUPREMACIA CONSTITUCIONAL DESDE UNA PERSPECTIVA MATERIAL: LA MUTACIÓN DE LA CONSTITUCIÓN MEDIANTE LA ASUNCIÓN POR EL ESTADO DE FINES DIFERENTES A LOS ESTABLECIDOS POR EL PODER CONSTITUYENTE. VII. CONSIDERACIONES FINALES. 


\title{
LA CRISIS DE LA CONSTITUCIÓN EN EL PROCESO DE INTEGRACIÓN EUROPEA*
}

\author{
POR \\ JAVIERTAJADURA TEJADA \\ Profesor titular de Derecho Constitucional \\ Universidad del País Vasco
}

\section{INTRODUCCIÓN}

En una brillante conferencia sobre los conceptos de legitimidad y representación políticas, aludía el profesor De Vega al meritorio ensayo de Ortega Esquema de la crisis, para señalar que las reflexiones sobre los conceptos básicos y fundamentales de la Teoría del Estado y de la Teoría de la Constitución, no pueden prescindir del contexto de crisis histórica que, por fortuna o por desgracia, nos ha tocado vivir.

En tiempos de crisis advertía Ortega lo que nos pasa es precisamente que no sabemos qué es lo que nos pasa. Resulta por ello evidente que la primera condición para poder salir de la crisis es tomar conciencia de ella, de su realidad y de su alcance. Y ello evitando tanto el error de realizar un diagnóstico simplificador y por tanto inútil de una realidad compleja como el otro extremo de complicar indebidamente lo sencillo impidiendo así cualquier análisis clarificador.

* El presente trabajo tiene su origen en la conferencia impartida por el autor el 19 de julio de 2001, en el marco del curso "Hacia una Constitución european, dirigido por el profesor Antonio Torres del Moral en Ávila. Agradezco al profesor Torres del Moral su invitación a ocuparme de tan importante tema en dicho curso y su posterior ofrecimiento a acoger la versión escrita de aquella intervención en estas páginas.

Igualmente, agradezco a los profesores Ruipérez y Roura las observaciones y sugerencias realizadas. 
En este sentido, el objeto de esta exposición es poner de manifiesto la profunda crisis que afecta a la categoría central del Derecho Constitucional, esto es la Constitución normativa, en el contexto politico, ideológico, económico, social y cultural determinado por el proceso de integración continental europeo iniciado por el Tratado de Roma hace medio siglo y cuyo último estadio viene configurado por elTratado de Niza en trámite de ratificación por los Estados miembros.

Naturalmente la toma de conciencia de esta crisis de la Constitución exige como tarea previa la definición de la categoría cuya crisis se analiza. En otras palabras, cualquier exposición sobre la crisis de la Constitución requiere afrontar previamente el problema de cuál sea el concepto político de Constitución.

Sobre la importancia de esto último creo oportuno subrayar unas palabras del profesor De Vega proferidas en la clausura de un provechoso y fructífero Congreso de Derecho Constitucional que tuvo lugar en Oñate, bajo la dirección del profesor García Herrera, en marzo de 1996 ${ }^{1}$. En la conferencia con la que se clausuró el Congreso, titulada "En torno al concepto político de Constitución», el profesor De Vega realizó una brillante sintesis de los problemas fundamentales a los que debe enfrentarse el constitucionalista en el momento actual $y$, entre otras cosas, afirmó lo siguiente: "No admite dudas que el primero y más formidable enigma ante el que el constitucionalista tiene que situarse en el presente es nada menos que el propio concepto político de Constitución, sobre el que se erige la Democracia Constitucional Contemporánea (...). Ocurre, sin embargo, que no son muchos quienes han querido o sabido correr el riesgo de colocarse directamente ante él (...) Lo que significa que el concepto político de Constitución no es ni mucho menos un tema concluso, sino, por el contrario, una cuestión abierta, y sobre la que de forma incidental e indirecta los juristas, les guste o no, se ven recurrentemente obligados a volver»².

Tres años después, en abril de 1999, y en el mismo marco, la antigua Universidad de Oñate, bajo la dirección de los profesores Corcuera y García Herrera, se celebró otro Congreso sobre "La protección de los

1 Todas las ponencias del Congreso fueron recogidas en un cuidado volumen en el que se realiza un sugerente repaso a los principales problemas del constitucionalismo actual. Garcia Herrera, Miguel Ángel (dir.), El constitucionalismo en la crisis del Estado Social, Servicio Editorial de la Universidad del País Vasco, Bilbao, 1997.

2 DE VEGA, Pedro: «En torno al concepto político de Constitución», en El constitucionalismo en la crisis del Estado social, ob. cit., pág. 704. 
derechos fundamentales en la Unión European. Allí el profesor Ruipérez recogió el guante lanzado por su maestro, el profesor De Vega, y presentó una sugerente exposición sobre el concepto político de Constitución, su indisoluble vinculación al principio democrático y a la teoría del poder constituyente, y su imposible aplicación en el momento actual al fenómeno resultante del proceso de integración europea. La sugerente intervención del Catedrático de La Coruña dio lugar posteriormente a una excelente monografía, La "Constitución europea" y la teoría del Poder Constituyente, de muchos de cuyos planteamientos soy deudor y que será frecuentemente citada a lo largo de mi exposición ${ }^{3}$.

El punto de partida inexcusable para cualquier reflexión sobre el tema que nos ocupa, es el reconocimiento de que el Estado, como Estado social en crisis, subsiste y que, en modo alguno, cabe pensar que, a corto o medio plazo, se pueda prescindir de él como marco político fundamental para expresar y garantizar el interés general. Ahora bien, dada la magnitud de los desafios y la complejidad de los problemas a los que han de hacer frente, los Estados europeos se hallan resueltos a "continuar el proceso de creación de una unión cada vez más estrecha entre los pueblos de Europa" para lo cual "han decidido crear una Unión Europea» 4 .

De esta manera, Europa, que hace veinticinco siglos alumbró la polis $y$ vio constituirse en el siglo XVI los primeros Estados nacionales, se dispone a crear una nueva forma de organización política, la Unión de Estados 4 bis.

El problema al que el constitucionalista ha de hacer frente es que siendo la Unión Europea una organización de Derecho Internacional, sus decisiones políticas y normas jurídicas se imponen sobre las de los Estados constitucionales, desvirtuando, en buena medida, el contenido democrático y social de las Constituciones nacionales. De lo que se trata, por tanto, es de alumbrar esa Unión de acuerdo con los principios inspiradores del constitucionalismo contemporáneo. De lograrlo, la crisis actual de las Constituciones nacionales se vería superada mediante la aprobación de una Constitución europea, de la Constitución de "una Europa social y democrática de Derecho" como la expuesta por el profesor Luis Jimena en una monografía con este mis-

3 Ruipérez Alamillo, Javier: La "Constitución europea» y la teoría del Poder Constituyente, Biblioteca Nueva, Madrid, 2000.

4 Preámbulo del Tratado de la Unión Europea (Tratado de Amsterdam).

4 bis Duvergen, Maurice: Europa de los hombres, Alianza, Madrid, 1994. 
mo título5. En caso contrario, la Constitución normativa, la Constitución democrática, perecerá en un proceso que informado sólo por la lógica del mercado, desembocará en una Constitución material que, si en palabras del maestro Mortati se compone de fines y fuerzas, vendrá configurada por fines y fuerzas tan ajenos al principio democrático como la estabilidad monetaria y el Banco Central Europeo 6 .

Tras estas consideraciones preliminares y meramente introductorias, procede poner de manifiesto la relevancia del principio democrático (del que el dogma de la supremacía constitucional no es sino el lógico corolario) como fundamento del constitucionalismo contemporáneo (II), y explicar después cómo y por qué las ideas constitucionales se consolidaron en Estados Unidos mucho antes y con mayor facilidad que en Europa (III). Una vez establecido lo anterior podremos abordar finalmente el tema central de esta exposición, la doble crisis que el concepto de Constitución debe afrontar en el proceso de integración europea: crisis formal (V) y material (VI).

\section{EL PRINCIPIO DEMOCRÁTICO COMO FUNDAMENTO DEL CONSTITUCIONALISMO CONTEMPORÁNEO}

En sentido moderno, técnico y actual sólo puede hablarse de Constitución, y constitucionalismo, a partir de un momento histórico muy concreto: el determinado por las grandes revoluciones liberal-burguesas, americana y francesa, de finales del siglo XVIII. Fue entonces cuando, con la confrontación de los principios teóricos de la ideología liberal encarnada en la obra de Montesquieu y los del pensamiento político democrático magistralmente formulados por Rousseau, hicieron su aparición en la historia los primeros textos que podemos denominar constitucionales. Textos que asumen la convergencia de los tres principios básicos del constitucionalismo contemporáneo: el principio democrático basado en la afirmación de que el titular del Poder Constituyente es el Pueblo, el principio liberal basado en la defensa y garantía de los derechos y libertades de la persona mediante las declara-

5 Jimena, Luis: La Europa Social y Democrática de Derecho, Dykinson, Madrid, 1997.

6 MoRTATI, Constantino: La Costituzione in senso materiale, Milán, 1940. TAJAdurA, Javier: «El Banco Central Europeo: su estatuto jurídico», en VV.AA.: La introducción de la moneda única europea en España, Sociedad Estatal de transición al euro, Madrid, 1999, págs. 91-101. 
ciones de derechos y la separación de poderes, y el principio de supremacía constitucional que afirma la sujeción del gobernante y del resto de los poderes constituidos y de todos sus productos normativos a la Constitución.

Aunque de todos esos principios, incluido el democrático, podemos encontrar valiosos antecedentes en la Historia de las Ideas Politicas, lo cierto es que nunca hasta entonces habian desplegado efectos concretos en la realidad y en la historia.

Limitando nuestra atención al principio democrático, que consideramos principio fundamental y omnicomprensivo en cierta manera de los demás, podemos decir que presupuesto inexcusable de su aparición fue el proceso de desacralización del Estado. En este sentido, la obra de Maquiavelo, "El Príncipe», constituye un hito de singular trascendencia. Como ha señalado el profesor De Vega, será a partir de entonces cuando surja la "creencia de que, al ser el Estado una obra humana, es al pueblo a quien corresponde el establecimiento de sus modos y formas de organización " ${ }^{7}$. Porque esto es así, «evidente resulta que el constitucionalismo aparece inescindiblemente unido al principio democrático, que se erige de manera inconcusa en el punto de arranque y fundamento último de la nueva forma de organización política del Estado" ${ }^{8}$. Es precisamente esta circunstancia la que va a marcar la diferencia entre el Estado Constitucional y el resto de las formas políticas que adoptó el Estado desde su nacimiento en el siglo XV. Sólo cabe hablar de Estado Constitucional en la medida en que éste basa su organización en un texto que es obra de la voluntad de un Pueblo que se sabe soberano y que se considera por ello el único sujeto legitimado para decidir cómo quiere ser gobernado.

Sin detenernos en los relevantes antecedentes teóricos del principio democrático hemos de reconocer que fue en 1620 cuando aquellos produjeron su primer efecto en la historia. Durante el viaje de los Padres Peregrinos en el Mayflower, mediante la transformación del pacto de gracia puritano en un auténtico pacto político se tomó plena conciencia de que el Pueblo es el titular de la soberania. En virtud de los planteamientos políticos del calvinismo se llegó a la conclusión de que si los individuos son totalmente libres para organizar su comunidad religiosa, lo son también para organizar su comunidad política.

7 DE VEGA, Pedro: "Constitución y democracia», en La Constitución de la monarquía parlamentaria (López Pina, A., ed.), FCE, Madrid, 1983, pág. 67.

8 RUIPÉREZ, Javier: La «Constitución europea»..., ob. cit., pág. 103. 
Fruto de esta nueva concepción de la comunidad política influenciada por el puritanismo calvinista son los primeros antecedentes de las Constituciones modernas y las primeras plasmaciones concretas del principio democrático. Principio que alcanzará su consagración definitiva cuando las colonias americanas se independicen de la Corona británica.

Como ha puesto de manifiesto Charles Borgeaud, fue en el ámbito de las futuras colectividades-miembros estadounidenses, y no en el de la Federación, donde se proyectó y se desarrolló la más correcta expresión de la teoría de la soberania popular: La organización del ejercicio del Poder Constituyente uestá basada no sólo sobre el principio de que la autoridad constituyente pertenece al Pueblo, sino también sobre esta otra concepción, retomada en el Derecho moderno por la Reforma puritana, que esta autoridad no puede ser representada " 9 . Y fue así como las antiguas colonias fueron aprobando sus respectivas Constituciones. Y lo hicieron, como lo han puesto de relieve los profesores De Vega y Ruipérez, siguiendo de un modo u otro los esquemas teóricos trazados, ya en 1717, por el reverendo John Wise, de forma que en aquellos procesos pueden fácilmente distinguirse tres etapas diferenciadas y sucesivas: declaración de derechos, pacto social y acto constitucional ${ }^{10}$.

Analicemos brevemente cada una de ellas. Por lo que se refiere a la primera etapa, resulta incuestionable el hecho de que la primera preocupación de los revolucionarios liberal-burgueses, tanto en Francia como en América, fue la de proceder al reconocimiento de la existencia de una esfera de libertad individual absoluta. Esa preocupación se tradujo en el plano normativo en las declaraciones de derechos fundamentales. Será en un momento posterior cuando se proceda a aprobar la Constitución y esto último se hará siempre, precisamente, para garantizar aquellos derechos mediante la separación de poderes. En cualquier caso lo que importa subrayar es que las declaraciones de derechos se configuran como un presupuesto inexcusable para la existencia misma del Estado Constitucional y que lo distinguen del Estado absoluto. Frente a las concepciones absolutistas según las cuales los privilegios son concesiones graciosas de los monarcas a las clases sociales más poderosas, se impone la tesis, tributaria de las doctrinas iusnaturalistas, de

9 BorgeaUd, Charles: Établissement et revision des Constitutions en Amérique et en Europe, París, 1893, pág. 166. Tomo la cita de RuIPÉREz, Javier: La "Constitución europea»..., ob. cit., pág. 106.

10 WISE, John: A Vindication for the Government of the New England Churches. A Drawn from Antiquity; the Light of Nature; Holy Scripture; its Noble Nature; and from the Dignity divine Providence has put upon it, Boston, 1772. (1. a edición, 1717). Agradezco al profesor Santiago Roura haberme facilitado copia de esta obra. 
que todo hombre por el hecho de serlo es titular de unos derechos preexistentes al Estado y que, por tanto, deben ser por él respetados.

La tercera etapa (dejemos de lado, por el momento, la segunda) es también fácilmente identificable en los procesos revolucionarios americano y francés. Una vez que, mediante la declaración de derechos, se ha establecido la esfera de libertad individual, de lo que se trata es de hacerla efectiva. En ello consiste el acto constitucional, en aprobar un Texto constitucional que organizando el Estado conforme al principio de división de poderes asegure al ciudadano el respeto a su ámbito de libertad personal.

Evidente resulta que este acto constitucional concebido como supremo sistema de garantía de la libertad individual requiere, por ineludible exigencia del racionalismo jurídico, su plasmación en un documento escrito, formal y solemne, aprobado por el Pueblo, titular del Poder Constituyente.

El segundo momento o etapa del proceso constitucional según el aludido esquema del reverendo Wise, el pacto social, resulta más difícil de identificar en la práctica, y ello porque se verifica al mismo tiempo que el acto constitucional. Sin embargo, a pesar de esa simultaneidad en el tiempo, lo cierto es que desde un punto de vista conceptual o teórico el pacto social es un momento clara y necesariamente diferenciado tanto de la declaración de derechos como del acto constitucional.

Probablemente debamos a Isnard una de las más precisas formulaciones de tan importante distinción. Reproduzco la cita que, aunque larga, considero imprescindible por la claridad que aporta sobre este tema: «Debe reconocerse en primer lugar (...) cuáles son los derechos naturales de todos y proclamarlos. (...) Para seguir el orden natural de la organización social hay que proceder, antes de toda ley constitucional, a la redacción de un pacto social. Este acto debe ser intermedio entre la declaración de derechos, que le sirve de base, y la Constitución, a la que sirve de barrera y regulador. Si el pacto social difiere de una simple declaración de derechos, difiere más aún de un acto constitucional. Hacer un pacto social es redactar el instrumento por el que ciertas personas consienten formar una asociación con tales o cuales condiciones previas. Hacer una Constitución, por el contrario, es únicamente determinar la forma de gobierno. (...) En un caso se crea la sociedad, en el otro se organiza»"11.

11 ISNARD, Archives Parlamentaires, vol. LXIV, pág. 417. Tomo la cita de DE VEGA, Pedro: «Mundialización y Derecho Constitucional: la crisis del principio demo- 
La relevancia de esta última distinción en relación con la aplicación del principio democrático no puede ser soslayada: «En un caso se crea la sociedad, en el otro se organiza" (Isnard). Y ello porque va a ser mediante el pacto social como surja el Poder Constituyente y como se configure, por tanto, el titular de la soberanía. Desde un punto de vista lógico resulta incuestionable que si la Constitución es el fruto de la voluntad del poder constituyente, el surgimiento de este último debe ser previo a aquélla. Así mediante el pacto social surge el Poder Constituyente, pero es mediante el acto constitucional como aquel actúa en la Historia.

La relevancia del pacto social en relación con la plasmación del principio democrático es notoria. En este sentido, el profesor Ruipérez ha señalado como "debe tomarse en consideración que cuando los distintos individuos, a través de su adhesión al pacto social, consienten en formar una asociación, es decir, en crear una única comunidad política -el Estado-como unidad organizada de decisión y acción política, lo que en realidad están haciendo es, por utilizar la figura acuñada por Althusius, culminar el proceso por el que cada uno de los individuos cede la soberanía que como tal le corresponde, en favor de una nueva entidad superior a cada uno de ellos, y englobadora de todos ellos: el Pueblon" ${ }^{12}$. Mediante la verificación del pacto social, el Pueblo queda afirmado como el único sujeto titular de la soberanía en el Estado. A partir de entonces, el Pueblo puede en virtud de su condición de soberano imponer su voluntad a los ciudadanos individualmente considerados, y por tanto, está facultado para aprobar, establecer y sancionar la Constitución.

Si analizamos el proceso de formación de los nuevos Estados norteamericanos y posteriormente el de la propia Unión, comprobamos sin dificultad que el principio democrático no encontró ningún obstáculo para su implantación. En las nuevas Repúblicas, desvinculadas de la Corona británica, el Pueblo y sólo él, se presenta como titular indiscutible del poder soberano, y en virtud de ello como sujeto habilitado para dotarse de una Constitución. El principio democrático se confirma en la práctica en la medida que se rechaza explícitamente la posibilidad de que dicho poder soberano sea representado.

crático en el constitucionalismo actual», en Revista de Estudios Políticos, núm. 100, 1998, pág. 28.

12 RuIPÉrez, Javier: La "Constitución europea»..., ob. cit., pág. 115. 
No parece necesario insistir más sobre la relevancia del principio democrático y en su carácter de fundamento del constitucionalismo contemporáneo. Baste recordar, a modo de sintesis de todo lo dicho, las celebérrimas palabras con las que se inicia el Preámbulo de la Constitución de Estados Unidos de Norteamérica: "Nosotros, el Pueblo...."13. Concisa y precisa plasmación jurídica del principio democrático manifestado en el pacto social. A partir de entonces podremos encontrar también en otros preámbulos constitucionales declaraciones similares del principio democrático, pero corresponde al Preámbulo americano el mérito de haber sido el primero en formularlo con tan meridiana claridad por lo que podemos considerar a dicho texto, en cierta medida, como el documento fundacional del constitucionalismo contemporáneo.

\section{LA DIFERENTE EVOLUCIÓN DEL CONSTITUCIONALISMO EUROPEO: LIBERALISMO DOCTRINARIOY NEGACIÓN DEL ESTADO CONSTITUCIONAL}

Aunque inspirados en los mismos principios liberal-democráticos (Montesquieu y Rousseau) los procesos revolucionarios burgueses desencadenados en Europa desde fines del siglo XVIII discurrieron por caminos distintos de los recorridos por el pueblo americano ${ }^{14}$. El factor determinante de las profundas diferencias que marcarán la evolución del constitucionalismo europeo, y de forma paradigmática del francés, no fue otro que la subsistencia de la institución monárquica. La presencia en la estructura del Estado de un monarca hereditario, titular de la Jefatura de aquél, es la causa directa e inmediata de que la historia del constitucionalismo europeo se explique en función de la permanente pugna entre el principio democrático y el principio monárquico.

13 Sobre el Preámbulo de la Constitución de EE.UU. y sobre el valor jurídico y función política de los Preámbulos, en general, en el constitucionalismo contemporáneo, TAJAduRA, Javier: El Preámbulo constitucional, Comares, Granada, 1997.

14 Resultan sumamente ilustrativas de las profundas diferencias entre ambos procesos, así como de las causas históricas, políticas e ideológicas que las explican las siguientes obras de FioravanTI, Mauricio: Constitución, Trotta, Madrid, 2001, y del mismo autor: Los derechos fundamentales. Apuntes de historia de las Constituciones, Trotta, Madrid, 3." edición, 2000. Imprescindible también, BLANCO, R.: El valor de la Constitución, Alianza Editorial, Madrid, 1994. 
- Estas circunstancias históricas son las que explican que los procesos constitucionales europeos se articulen sobre un principio totalmente diferente al vigente en Estados Unidos. En Europa se admitirá que el poder soberano puede delegarse y ello se hará a través del instituto de la representación política con mandato libre.

Frente a la democracia de la identidad propugnada por Rousseau, en Europa se impondrá la democracia representativa en el marco del esquema trazado por Emmanuel-Joseph Sieyès. Según el abate revolucionario, la Nación es la titular de la soberanía y como tal a ella corresponde la facultad de darse una Constitución. Ahora bien, dado el carácter abstracto que la Nación reviste, dicha facultad sólo puede ser ejercitada por los representantes de aquella. De esta forma se entiende que los representantes de la Nación, es decir, el Parlamento, reciben de ella el poder de elaborar, aprobar y sancionar la Constitución.

No es preciso detenernos más en este punto. De lo dicho se concluye sin dificultad que el principio democrático experimenta una notable conmoción. En última instancia ocurre que el Pueblo ha dejado de ser soberano, y que toda la problemática del poder constituyente se ha trasladado al ámbito de las Asambleas parlamentarias.

La asunción de las tesis de Sieyès determinó, entre otras cosas, como veremos después, la imposibilidad de configurar la Constitución como auténtica norma suprema, relegándola al nivel de la ley ordinaria, al de un producto normativo más de la Asamblea parlamentaria. Pero además, $y$ esto es lo que ahora nos interesa subrayar, desvirtuó por completo la vigencia y efectividad del principio democrático tal y como había sido entendido y aplicado al otro lado del Atlántico.

En este contexto, la cuestión que inevitablemente se plantea es, en palabras del profesor Ruipérez, la siguiente: "¿Cómo puede seguir afirmándose que el Pueblo es soberano cuando, en el marco de la Democracia representativa, aparece la distinción entre gobernados y gobernantes, siendo estos últimos quienes, en cuanto representantes, elaboran y aprueban realmente el Código Fundamental?»"15.

La respuesta nos la proporciona el profesor De Vega: «La necesidad de hacer valer, conforme al principio democrático, la suprema autoridad del pueblo frente a la autoridad del gobernante, no ofrece otra posibilidad ni otra alternativa que la de establecer, por el propio 
pueblo, una ley superior (la Constitución), que obligue por igual a gobernantes y gobernados. En contraposición a los poderes constituidos (los gobernantes), ordenados y limitados en la Constitución, aparece de este modo, como poder previo ilimitado y total el poder constituyenten ${ }^{16}$.

Solamente aceptando lo anterior es posible entender la Constitución como tal, es decir, como una auténtica norma jurídica suprema de un Estado. Lo cual quiere decir, y esto es lo que interesa retener para el seguimiento de esta exposición, que el principio democrático conduce, inexorablemente, al principio de supremacía constitucional que no es más que su lógico correlato.

Ello va a determinar, como tendremos después ocasión de analizar con detalle, que las profundas conmociones que atraviesan actualmente los textos constitucionales de los países miembros de la Unión Europea y que ponen en cuestión, tanto desde un punto de vista formal como desde un punto de vista material, el dogma de la supremacía constitucional, afectan de forma grave e intensa al principio democrático, auténtico fundamento político de aquél.

Pero vayamos por partes. Para que el principio democrático y el de supremacia constitucional alcancen efectividad es preciso previamente implantar la tesis de la rigidez constitucional. Tesis que si en el plano teórico fue magistralmente formulada por James Bryce ${ }^{17}$, encontró aplicación práctica por primera vez en el artículo $V$ de la Constitución norteamericana, permitiendo asi distinguir con claridad la doble oposición Poder Constituyente/Poder de Reforma/legislador ordinario y Constitución/Reforma constitucional/Ley ordinaria. Solamente estableciendo un procedimiento especifico, diferente y más agravado que el legislativo ordinario, para llevar a cabo la revisión de la Constitución, su carácter de norma suprema queda garantizado.

Como es sabido esto no ocurrió en Europa hasta bien entrado el siglo XX. Es decir que, a pesar de basarse en unos presupuestos comunes, la evolución del constitucionalismo europeo fue muy diferente de la del norteamericano. Hasta tal punto esto es así que podemos decir que en Europa el principio democrático brilló por su ausencia durante todo el siglo XIX, lo cual nos obligaría en puridad a descalificar como

16 De Vega, Pedro: La reforma constitucional y la problemática del Poder constituyente, Tecnos, Madrid, 1985, pág. 25.

17 Bryce, James: Constituciones flexibles y Constituciones rígidas, Centro de Estudios Constitucionales, Madrid, 1988. 
constitucionales a los Códigos Políticos fundamentales de aquella centuria, o todo lo más a referirnos a ellos como textos seudoconstitucionales.

En Francia en particular y en Europa en general, la doctrina de Sieyès condujo a la creencia de que las asambleas parlamentarias en cuanto representantes del soberano, son ellas mismas soberanas. $Y$ lo son no únicamente durante el proceso constituyente, lo que hubiera sido admisible, sino, y aquí es donde la estructura del Estado Constitucional sufre una inevitable fractura, durante toda la vida del Estado.

Las consecuencias de esta doctrina son evidentes. Se subordina la Constitución a los mudables intereses de las mayorías parlamentarias, mayorías que se convierten en auténticos poderes constituyentes, y por lo tanto, aunque el resultado sea completamente absurdo, poderes absolutos e ilimitados en el contenido material de su voluntad, sujetos, por tanto, sólo a límites formales o procedimentales de actuación.

Si la gravedad de tales consecuencias no puede dejar de advertirse, preciso es recordar que el contexto ideológico e histórico de la Europa decimonónica complica todavía más las cosas. Este contexto es el determinado por el liberalismo doctrinario y los regímenes políticos que bajo dicha ideología encontraron cobertura. Regímenes como el francés de 1814 o el español de 1834, no basados en Constituciones auténticas sino en meras Cartas otorgadas. Esto es, no basados en el poder constituyente del pueblo sino en la concesión graciosa del monarca.

El liberalismo doctrinario, en su aparente empeño en conciliar los intereses del monarca, partidario en última instancia de recuperar el poder absoluto que durante el Antiguo Régimen habia detentado, con las nuevas ideas surgidas de la revolución liberal-burguesa según las cuales la soberanía corresponde al Pueblo o a la Nación, acuñó la insostenible tesis de la soberanía compartida. Según esta la soberanía va a corresponder tanto al Rey como a la Nación. Surge asi un nuevo marco politico en el que el monarca y el Parlamento, que en virtud del sufragio censitario se configuraba como la representación de la oligarquía burguesa, son los protagonistas indiscutibles. El problema que tan alto protagonismo plantea no es otro que el de que siendo el Rey y el Parlamento oligárquico-burgués los titulares de la soberanía, ambos se configuran simultáneamente como Poder Constituyente del Estado y poderes constituidos del mismo. 
El Rey y el Parlamento como titulares de la soberania y del poder constituyente son los autores de la Constitución y por lo tanto la preceden. Ahora bien, al mismo tiempo, como órganos o instituciones del Estado son poderes constituidos y por tanto destinatarios de las normas constitucionales.

Evidente resulta que si la esencia del Estado Constitucional reside en la distinción entre Poder Constituyente y poderes constituidos, el rechazo de esta distinción, lo que en último término implica, no es otra cosa que la negación del propio Estado Constitucional. A la misma conclusión llegamos si tenemos en cuenta que es también una exigencia inexcusable del Estado Constitucional que el Poder Constituyente una vez actúa aprobando la Constitución desaparezca, mientras que en los Estados de la Europa decimonónica se pretendia perpetuar indefinidamente su actuación.

De esta forma, la negación de la teoría democrática del Poder Constituyente del Pueblo, produjo, inevitablemente, la falsificación de los otros principios inspiradores del constitucionalismo contemporáneo: el liberal y el de supremacía constitucional.

El principio liberal era negado en la medida en que conservando el monarca su condición de soberano se hacía imposible organizar el Estado conforme al principio de la división de los poderes.

Por otro lado, todo ello se traducia en el plano normativo, en la imposibilidad de configurar la Constitución como norma suprema. El principio de supremacia constitucional era inviable desde el momento mismo en que se rechazaba la distinción entre Poderes Constituyentes y Poderes constituidos. La Constitución se transformaba en una Ley Ordinaria. No se preveían procedimientos especiales de reforma constitucional en tanto que la Constitución no era sino un producto normativo más del Parlamento. Dicho con otras palabras, si la teoría democrática del poder constituyente del pueblo requiere para su plasmación efectiva del principio de rigidez constitucional, la insostenible tesis de la soberanía compartida, fundamento básico de la ideología doctrinaria, conduce, inexorablemente, a la Constitución flexible que es tanto como decir a la negación de la Constitución.

De todo lo anterior podemos concluir como lo hace el profesor Ruipérez afirmando que, lejos de venir a consolidar el Estado Constitucional, lo que hizo en realidad el liberalismo doctrinario fue hacerlo inviable: «En efecto, en la medida en que, bajo su influencia política, se verifica la más rotunda negación de todos los principios inspirado- 
res del constitucionalismo moderno, y de manera fundamental la del principio democrático como clave de bóveda del sistema, lo que el doctrinarismo liberal produjo fue un pseudo-constitucionalismo, que para lo que en verdad servía era para enmascarar situaciones de dictadura más o menos encubiertan ${ }^{18}$.

En Europa habrá que esperar al final de la Primera Guerra Mundial, y de forma ya definitiva, al final de la Segunda, para que el seudoconstitucionalismo liberal sea sustituido por un auténtico constitucionalismo democrático y social.

Es decir, será definitivamente a partir de 1945 cuando los presupuestos ideológicos del constitucionalismo (principios democrático, liberal y de supremacia constitucional) sean plenamente aceptados en Europa y por tanto cuando las Constituciones puedan configurarse como tales, es decir, como normas jurídicas supremas emanadas de la voluntad soberana del Pueblo, concebido como único sujeto posible titular del poder constituyente.

Ahora bien, la afirmación sin ambages del principio democrático va a generar notables cambios en la articulación del proceso constituyente. "Cuando el principio democrático se admite sin ningún tipo de salvedades - escribe De Vega - y cuando se está dispuesto, además, a operar con él hasta sus últimas consecuencias, la mecánica del proceso constitucional, tal y como se planteó en el Estado Liberal Burgués (...) ya no podrá ser la misma. Cambia el orden de los acontecimientos, pero cambia también, y sobre todo, el contenido y alcance de cada uno de los supuestos de ese proceso" ${ }^{19}$.

En este nuevo contexto, el proceso constituyente deja de tener su punto de arranque en la declaración de derechos y se inicia con el pacto social por el que nace el nuevo Poder Constituyente soberano, continúa con el proceso de elaboración y aprobación de la Constitución en la que queda incluida la tabla de derechos fundamentales.

Este cambio en el orden de los acontecimientos del proceso constituyente tiene una gran relevancia en orden al significado y a la garantía de los derechos fundamentales. Como ha puesto de manifiesto Ruipérez, «ahora, las declaraciones de derechos pierden esa fuerte carga iusnaturalista con la que aparecian investidas en el viejo Estado liberal, para convertirse, $y$ esto es lo que realmente es impor-

18 RUIPÉREZ, Javier: La "Constitución europea»..., ob. cit., pág. 134.

19 DE VEGA, Pedro: «En torno al concepto...», ob. cit., pág. 715. 
tante y resulta trascendente, en Derecho Positivo cuya fuerza normativa se encuentra en la voluntad del Poder Constituyente» ${ }^{20}$.

Por otro lado, el tránsito del Estado liberal al Estado Social no sólo supuso la afirmación del principio democrático sino que implicó también la incorporación a la Constitución de una elevada densidad de contenidos. "Ya no se trataba de salvaguardar sólo la regulación, limitación, organización y equilibrio de los poderes, o enunciar los derechos y libertades civiles y políticas -escribe García Herrera- sino que es necesario precisar las demandas que la sociedad eleva al poder, la nueva relación entre política y economía, las técnicas de intervención mutua entre el Estado y la sociedad „21. En este sentido, continúa el autor citado, "ya no bastaba la concisión liberal puesto que se exigía la definición de los fines del Estado y la consagración de los derechos prestaciones que respondian a intereses sociales hasta entonces desatendidos y que representaban un intento de corregir los desequilibrios y formalismos decimonónicos "22. En todo caso, concluye el profesor García Herrera, y esto es lo que conviene subrayar en orden a nuestra exposición, "se trataba con las nuevas constituciones de perseguir la materialización de una indeterminada igualdad sustancial, cuyos difusos contornos eran esbozados en la Constitución pero que,

20 RuIPÉREZ, Javier: La «Constitución europea»..., ob. cit., págs. 136-137. «EI reconocimiento del principio democrático - ha escrito De Vega - lo que introduce e impone es, precisamente, la lógica contraria (a la del Estado liberal). Los derechos empiezan a valer en la medida en que la Constitución -que es una norma juridica - los reconoce, al tiempo que establece un doble principio de jerarquía y especialidad para su realización efectiva». DE VEGA, Pedro: "En torno al concepto...», ob. cit., pág. 717. Estas consideraciones nos ponen de manifiesto el verdadero y limitado significado y alcance del debate de la Carta Europea de Derechos Fundamentales. Finalmente en el Consejo Europeo celebrado en Niza en Diciembre del 2000 se decidió no atribuirle un valor jurídico sino meramente político con lo cual elTexto en cuestión carece de garantías jurisdiccionales. Ahora bien, aunque el Consejo le hubiera atribuido valor jurídico y como tal lo hubiera incorporado al Tratado de la Unión, su naturaleza sería la de una Declaración de Derechos contenida en un Tratado Internacional que como tal goza por definición y por su propia naturaleza de menores garantías que las que ofrece una Constitución normativa. En última instancia ocurre, y eso es algo que no debiera sorprendernos, que se está operando con el esquema liberal según el cual la Declaración de Derechos precede al pacto social y al acto constitucional.

21 Garcia HerRera, Miguel Ángel: "Rigidez constitucional y Estado social", en VV.AA.: La experiencia jurisdiccional: del Estado legislativo de Derecho al Estado constitucional de Derecho, Escuela Judicial-Consejo General del Poder Judicial, Madrid, 1998, pág. 54

22 lbidem. 
en todo caso, proporcionaban un fundamento preciso para reclamar la materialización y para impedir retrocesos respecto a los niveles alcanzados en el texto de las normas constitucionales que traducian la compatibilidad de intereses y el desarrollo de la conciencia social respecto a principios, valores y formas de distribución „23.

\section{SUPREMACÍA CONSTITUCIONAL, DERECHO INTERNACIONAL Y DERECHO COMUNITARIO}

Afirmado, por fin, tras el largo proceso expuesto en el epígrafe anterior, el principio político democrático y su traducción jurídica, el de supremacía constitucional ${ }^{23}$ bis, éste necesariamente desplegó sus efectos sobre cualquier tipo de norma juridica.

Así, el dogma de la supremacía constitucional despliega sus efectos no sólo frente a las normas internas sino también frente a las normas internacionales. Y ello con independencia de la adscripción monista o dualista tradicional del ordenamiento de que se trate ${ }^{24}$. La subordinación de las normas jurídicas internacionales a la Constitución es un dato que no puede ser puesto en cuestión.

Dicha subordinación es una consecuencia lógica del principio de supremacia constitucional $y$, en este sentido, no resulta necesario que un ordenamiento constitucional dado lo recoja expresamente. Sin embargo, la Constitución española de 1978 sí lo ha hecho, y así, el apartado primero de su artículo 95 dispone que "la celebración de un tratado internacional que contenga estipulaciones contrarias a la Constitución exigirá la previa revisión constitucional»".

La doctrina, tanto internacionalista como constitucionalista, ha subrayado el carácter paradójico de esta disposición que ratifica la

23 Ibidem.

23 bis Para lo cual fue imprescindible también la aparición y consolidación de las jurisdicciones constitucionales.

24 Los paises de tradición monista se caracterizan porque en ellos la aplicabilidad de la norma internacional no requiere de una norma de recepción interna que les dote de eficacia, mientras que en los paises de tradición dualista si requieren el auxilio de aquélla para que la norma externa se considere integrada en el ordenamiento estatal. La Constitución española adopta una posición monista en tanto que según el artículo 96 , la incorporación al ordenamiento interno de una norma internacional válidamente suscrita por el órgano competente sólo requiere su publicación oficial. 
supremacía constitucional pero a costa de que sea la propia norma constitucional la que ceda en el conflicto planteado con la proyectada norma internacional. Puesto que, en efecto, lo que el artículo 95 prevé es un mecanismo para conciliar, en caso de conflicto, las normas constitucionales y las internacionales, estableciendo, como requisito para poder incorporar válidamente éstas en el ordenamiento interno, la necesidad de una previa reforma constitucional.

Esto es expresión de una concepción favorable al Derecho Internacional y de apertura al mismo, por parte del constituyente de 1978, quien ya desde entonces era consciente de esa nueva dimensión del Estado, como estado internacionalmente integrado o, como más específicamente ha señalado el profesor Pérez Calvo, de su carácter de Estado comunitario. Carácter que reviste nuestro Estado Constitucional desde la adhesión de España a las Comunidades Europeas en 198625.

Por otro lado, el principio de supremacía de la Constitución respecto a las normas internacionales se perfecciona con el procedimiento que permite someter aquellas al control de constitucionalidad interno. Esto es lo que hace precisamente el segundo párrafo del artículo 95 de la Constitución española.

Los problemas surgen en el momento en que existe otra disposición constitucional, el artículo 93 (introducido expresamente en el texto constitucional por el constituyente de 1978 con objeto de permitir la incorporación de España a las Comunidades Europeas) que establece que use podrá autorizar la celebración de tratados por los que se atribuya a una organización o institución internacional el ejercicio de competencias derivadas de la Constitución» ${ }^{26}$.

Durante bastantes años se discutió sobre si la habilitación contenida en el artículo 93 era o no una lex specialis en relación con los límites constitucionales establecidos en el artículo 95. Asi hubo quienes defendieron la tesis de la autonomía del proceso de integración europea, alegando que la cobertura del artículo 93 le eximía de los límites establecidos en el artículo 95. Afortunadamente, el Tribunal Constitucional puso las cosas en su debido lugar con su Declaración de 1

25 Pérez Calvo, Alberto: “La dimensión comunitaria del Estado en Europa Occidental», en Civitas Europa, núm. 1, 1998, págs. 19-35.

26 Sobre el capítulo III del Título III de la Constitución (arts. 93 a 96) resulta muy esclarecedor el comentario de Antonio REMIRO BROTONS en Comentarios a la Constitución española de 1978, dirigidos por O. Alzaga, Cortes Generales, Edersa, Madrid, 1998, vol. VII, págs. 491-650. Sobre el significado del art. 93 de la Constitución, Pérez Tremps, Pablo: Constitución española y Comunidad Europea, Madrid, 1994. 
de julio de 1992. Allí afirmó rotundamente, con meridiana claridad y evidente acierto, que los límites del artículo 95 son aplicables a todo tipo de Tratados internacionales, incluidos por tanto, también, los comunitarios estipulados al amparo del articulo 93.

De lo que antecede podemos concluir que el dogma de la supremacía constitucional despliega sus efectos también sobre los procesos de integración supranacional, como es el caso, del proceso de integración europea. Ello exige reconocer que desde la perspectiva del Derecho Constitucional español, la aplicabilidad de las normas jurídicas comunitarias dependerá, en última instancia, de la Constitución.

\section{LA CRISIS DEL PRINCIPIO DE SUPREMACÍA CONSTITUCIONAL DESDE UNA PERSPECTIVA FORMAL: LA APORÍATEÓRICA ENTRE LAS PRETENSIONES DE SUPREMACÍA DE LOS ORDENAMIENTOS CONSTITUCIONALY COMUNITARIO}

Ocurre sin embargo que, a pesar de dicha conclusión, no podemos considerar el problema resuelto y ello por las características propias que el fenómeno de integración europea presenta. Por lo que a nuestro tema se refiere bastará con que aludamos brevemente a uno de los caracteres esenciales del derecho comunitario europeo: el principio de primacía. Como es sabido, ha sido el propio Tribunal de Justicia de las Comunidades Europeas quien, en una labor meritoria desde la perspectiva de la integración, ha "creado" los principios y caracteres básicos del Ordenamiento jurídico comunitario, principios y caracteres como es el de la "primacía» que son los que permiten precisamente calificar al Derecho comunitario como un auténtico Ordenamiento Jurídico ${ }^{27}$.

En este sentido, para el Alto Tribunal Europeo, las normas del derecho comunitario, originario y derivado, se imponen siempre frente a las normas de derecho interno, cualquiera que sea su rango, es decir también frente a las de rango constitucional. Nunca se insistirá bastante en la importancia de la Sentencia Costa-Enel, de 15 de julio de $1964^{28}$. Esta resolución supuso un duro golpe al principio de supre-

27 Por todos, IsAAC, Guy: Droit communautaire général, París, 4." edición, 1995, y DIEZ DE VELASCO, Manuel: Las organizaciones internacionales, 11. "edición, 1999, págs. 641 y ss.

28 Un sugerente comentario de la sentencia en PUENTE EGIDo, José: Casos prácticos de Derecho Internacional Público, 3. "edición, Madrid, 2000, págs. 395-408. 
macia constitucional pocos años después de que éste hubiera conseguido desplegar todos sus efectos en la mayor parte de los Estados del Occidente europeo.

El Tribunal de Justicia ha configurado al Derecho Comunitario como una suerte de "supraconstitución" que se impone a los ordenamientos internos, y ante cuyas normas las de estos últimos han de ceder siempre ${ }^{29}$.

Como ha advertido el profesor Garcia-Herrera, «en las últimas décadas se ha procedido a una creciente autonomización del ordenamiento comunitario hasta el punto de formalizar la disposición en su seno de un nivel constitucional que cierra $y$ unifica el conjunto. A pesar de su original procedencia internacional y de su dependencia de la voluntad de los Estados, por medio de la jurisprudencia delTJCE se ha impulsado un proceso de autorreflexividad de forma que se apela en exclusiva a los principios, normas e instituciones del ordenamiento comunitario, prescindiendo del condicionante de la fuente matriz de los ordenamientos estatales» ${ }^{30}$.

La consideración del Derecho Comunitario como un Ordenamiento Jurídico autónomo del de los Estados miembros no significa en la práctica otra cosa que la subordinación de éstos a aquél ${ }^{31}$. Que esto es así es difícilmente discutible. Ahora bien, ello no quiere decir que desde una perspectiva estrictamente constitucional no sea cuestionable. Sorprende por ello el acrítico fervor con que en numerosas ocasiones se describen estos fenómenos por parte de la doctrina.

La mejor doctrina, sin embargo, no ha podido eludir tales problemas (Balaguer, De Vega, Garcia-Herrera, López Basaguren, Ruipérez).

Así, el profesor López Basaguren en un brillante trabajo titulado de forma muy ilustrativa: «¿Réquiem por la Constitución? El ordena-

29 Fernandez Esteban, María Luisa: "La noción de Constitución europea en la jurisprudencia delTribunal de Justicia de las Comunidades Europeas", en Revista Española de Derecho Constitucional, núm. 40, 1994, págs. 241 y ss. pág. 77.

30 García Herrera, Miguel Ángel: «Rigidez constitucional...», ob. cit.,

31 El profesor Balaguer ha advertido que en el actual estadio de transición en que nos encontramos, existe una carencia de reglas precisas que regulen las relaciones entre los ordenamientos estatales y el comunitario. BALAGUER CALLEJON, Francisco: "La constitucionalización de la Unión Europea y la articulación de los ordenamientos europeo y estatal"n, en García Herrera, M. A. (dir.), El constitucionalismo..., ob. cit., págs. 592 y ss. 
miento constitucional en la integración comunitaria» ${ }^{32}$ ha puesto claramente de manifiesto como ha surgido una aporía entre el principio de supremacía constitucional, sobre el que se asientan los ordenamientos internos, por una parte, y el principio de primacía del derecho comunitario, y su "constitucionalización», que se ha configurado como la característica esencial de este ordenamiento. Es decir, "la aporía entre la respectiva pretensión de primacia que caracteriza, por igual, tanto a los ordenamientos internos como al ordenamiento comunitario. Aporía que se presenta en toda su radicalidad en los supuestos en que, junto a la existencia del órgano jurisdiccional comunitario encargado de garantizar la primacía de este ordenamiento, concurren órganos jurisdiccionales internos cuya misión, como juez de la constitucionalidad, es precisamente, la de asegurar la supremacía constitucional» ${ }^{33}$.

El conflicto entre la lógica constitucional y la lógica comunitaria concluyó en una primera etapa con la retirada de los Tribunales Constitucionales que acabaron aceptando en la práctica la doctrina jurisprudencial comunitaria. Pero, como pudo comprobarse más tarde, se trataba de un cierre en falso del problema. Efectivamente, en la medida en que el proceso de integración experimentaba avances sustanciales con la firma del Acta Única Europea y, sobre todo, con la importante profundización en la integración que implicó el Tratado de la Unión Europea, se inicia, como bien ha analizado el profesor López Basaguren, "una relectura constitucionalista del proceso de integración comunitaria, con la consiguiente (re)activación de las reservas de constitucionalidad, que, aunque latentes, no habían dejado de estar presentes desde el inicio del proceso de integración ${ }^{34}$.

Esa relectura va a determinar la activación de los mecanismos de reforma constitucional en gran parte de los Estados miembros. Los poderes constituyentes constituidos o derivados, ausentes hasta entonces del proceso de integración, se convierten en actores relevantes del mismo. Esto ocurre de forma especialmente destacable en Alemania y en Francia.

32 López BASAguren, Alberto: “¿Réquiem por la Constitución? El ordenamiento constitucional en la integración comunitaria», en Civitas Europa, núm. 2, 1999, págs. 7 a 31.

33 lbid., pág. 14.

34 Ibid., pág. 17. WEBER, Albrecht: «EJ control del Tratado de Maastricht por la jurisprudencia constitucional desde una perspectiva comparada", en Revista Española de Derecho Constitucional, núm. 45, 1995, págs. 31 y ss. 
En Alemania, una vez efectuada la reforma constitucional, el Tribunal Constitucional tuvo que pronunciarse sobre la compatibilidad del Tratado de la Unión con la Constitución alemana. En su célebre sentencia de 12 de octubre de 1993 sobre Maastricht, el Alto Tribunal Alemán determinó que el juez de la constitucionalidad dispone de la capacidad de controlar el respeto por parte de los órganos comunitarios del ámbito competencial atribuido a las Comunidades en los Tratados ${ }^{35}$.

Sobre esta sentencia mucho es lo que se ha escrito, a favor $y$ en contra. Ahora bien, difícilmente puede negarse el hecho de que es un alegato en defensa del principio democrático, lo que, en mi opinión, la hace plausible desde una perspectiva constitucional, es decir, desde el respeto al principio de supremacía constitucional, que es la posición adoptada como punto de partida en esta exposición.

ElTribunal Constitucional alemán afirma con rotundidad que «a la expansión de funciones y competencias de las Comunidades Europeas le pone coto el principio democrático». Por ello, «si instituciones $u$ órganos europeos dieran en gestionar o desarrollar el Tratado de la Unión de manera que no quedase cubierto por elTratado en que se funda la Ley de Ratificación, no serian vinculantes en la jurisdicción alemana los actos jurídicos que de él se desprendiesen». Los órganos del Estado alemán tendrían un impedimento de índole jurídico-constitucional para aplicar tales actos jurídicos en Alemania. En consecuencia, el Tribunal Constitucional alemán está examinando si los actos juridicos de instituciones y órganos europeos respetan las fronteras de los derechos de soberania a ellos otorgados o si, por el contrario, rompen ese marco.

De esta forma, lo único que hace el Tribunal Constitucional Alemán es recordar algo tan sencillo y evidente, pero que no se había explicitado lo suficiente, como que la autorización parlamentaria para ratificar el Tratado de la Unión no es un cheque en blanco a las instituciones comunitarias, $y$ en la medida en que los gobiernos nacionales ocupan un papel esencial en ellas (Consejo de Ministros y Consejo Europeo), a los gobiernos de los Estados. De otro modo, los edificios constitucionales que tan laboriosamente se han ido construyendo en Europa durante los últimos doscientos años se derrumbarian.

35 StEin, Torsten: "La sentencia del Tribunal Constitucional alemán sobre el Tratado de Maastricht", en Revista de Instituciones Europeas, núm. 3, 1994, págs. 745 y ss. ALAEZ CORRAL, Benito: "Comentario a la STC alemán de 12 de octubre de 1993", en Revista Española de Derecho Constitucional, núm. 45, 1995, págs. 243 y ss. 
Ahora bien, con estos planteamientos, intachables desde una óptica constitucional, evidente resulta que la aporía denunciada por el profesor López Basaguren vuelve a ocupar un lugar esencial en el debate jurídico europeo.Y ello por la sencilla razón de que la supervivencia del Ordenamiento comunitario exige, inexcusablemente, la primacía de sus normas ${ }^{36}$.

En cualquier caso, de lo hasta ahora expuesto cabría deducir que la supremacía constitucional está garantizada. El Tribunal Constitucional (alemán) la ha restituido al lugar central que debe ocupar en todo Estado constitucional y los demás órganos de Justicia Constitucional del resto de los Estados miembros pueden hacerlo con iguales argumentos y legitimidad.

Sin embargo, no creo que eso sea lo que ha ocurrido en la práctica. Solamente un análisis puramente formal del problema que nos ocupa podría llegar a tal errónea conclusión. Efectivamente, reforma constitucional y control de constitucionalidad de los Tratados son, como hemos visto, elementos indispensables de garantía de la supremacía constitucional. Pero no son suficientes, o al menos, no han podido impedir en la práctica importantes y trascendentales mutaciones constitucionales que ${ }^{37}$, en algunos casos, son auténticas violaciones o falseamientos de los Textos fundamentales.

\section{LA CRISIS DEL PRINCIPIO DE SUPREMACIAA CONSTITUCIONAL DESDE UNA PERSPECTIVA MATERIAL: LA MUTACIÓN DE LA CONSTITUCIÓN MEDIANTE LA ASUNCIÓN POR EL ESTADO DE FINES DIFERENTES A LOS ESTABLECIDOS POR EL PODER CONS- TITUYENTE}

El profesor Garcia Herrera ha analizado con gran agudeza este fenómeno en un interesante trabajo titulado "Rigidez constitucional y

36 Y la aporía continuará mientras no tenga lugar la aprobación de una Constitución de la Unión Europea.

37 Sobre el concepto de mutación constitucional, JeLLINEX, George: Reforma y mutación de la Constitución, Madrid, 1991. Hsu DaU-LIN: Mutación de la Constitución, Oñate, 1998. HeSSE, Konrad: Escritos de Derecho Constitucional, 2.` edición, Madrid, 1992, págs. 79 a 104. DE VEGA, Pedro: La reforma constitucional y la problemática del poder constituyente, Madrid, 1985. Advierte De Vega en esta última obra cómo, en cualquier caso, el problema básico que plantea la figura de la mutación es el de su legitimidad. 
Estado Social»38. En él pone claramente de manifiesto tanto la trascendencia del tema de la supremacía constitucional como la insuficiencia del análisis exclusivamente dogmático del mismo. Considero oportuno reproducir las consideraciones metodológicas con las que inicia su reflexión y que comparto plenamente: «El problema de la rigidez constitucional enlaza con una compleja y articulada relación de conceptos dogmáticos referidos todos ellos a aspectos centrales de la Constitución (...)Pero como se ha puesto de relieve resulta inadecuada una perspectiva exclusivamente dogmática que se conforme con una elaboración abstracta y general con la que se delimiten las categorías habituales desconociendo el contexto histórico y social en el que se desenvuelven (...) Si en cualquier circunstancia esta prevención metodológica resulta conveniente, es más imprescindible cuando estamos frente a procesos históricos como (...)el continuo impulso de integración europea, o la adaptación de las Constituciones del Estado Social a las condiciones de la globalización ${ }^{39}$.

Una de las señas de identidad de las constituciones europeas contemporáneas es la explicitación en ellas de los fines del Estado. Frente a la concisión del constitucionalismo liberal, el constitucionalismo social se caracteriza por la asunción constitucional de determinados objetivos de transformación social.

En relación con estos fines del Estado Social español el impacto producido sobre los mismos por los Tratados comunitarios es de tan intensidad y envergadura que, voy a referirme solamente a una cuestión de extraordinaria gravedad.

Como ha puesto de manifiesto el profesor García Herrera, es preciso subrayar como «los Tratados de la Unión Europea en sus dos últimas versiones de Maastricht y Amsterdam han avanzado en la determinación y concreción del soporte axiológico y finalístico de la construcción institucional ${ }^{40}$ y lo han hecho invirtiendo las coordenadas propias del Estado Social.

El artículo 9. 2 de la Constitución española, de la misma forma que el artículo 3 de la Constitución italiana, explicita el fin fundamental del Estado Social español, forma histórica adoptada por el constituyente de 1978. Dicha disposición se configura como la más clara con-

38 GarCla Herrera, Miguel Ángel: "Rigidez constitucional y Estado social...", ob. cit.

39 Ibid., págs. 35-36.

40 lbid., pág. 79. 
creción de los enunciados preambulares. Porque preciso es recordar que nuestra Constitución contiene una declaración ejemplar cuya potencialidad no ha sido suficientemente desarrollada, probablemente por estar ubicada en el Preámbulo de la misma y por la poca importancia que, aunque con muy relevantes excepciones (Pérez Serrano, Lucas Verdú, Vanossi o Häberle) la doctrina ha concedido a los preámbulos constitucionales ${ }^{41}$. Función esencial de un Preámbulo es recoger el techo ideológico del régimen y en ese sentido sintetizar los fines de un Estado constitucional dado. En el caso español el constituyente de 1978 proclamó como objetivo primordial el establecimiento en España de una sociedad democrática avanzada lo cual exige inexcusablemente el correspondiente deber de los poderes públicos de lograr la igualdad sustancial de los ciudadanos (art. 9. 2) ${ }^{42}$.

Ahora bien, el Estado español al que el constituyente le fijó como objetivos esenciales identificadores de su misma forma histórica, el establecimiento de una sociedad democrática avanzada, y el logro de la igualdad sustancial de todos los ciudadanos, asume la obligación de subordinarlos a las exigencias del respeto a los principios de economía de mercado y de libre competencia (art. 4. 1TUE) y al mantenimiento de la estabilidad de los precios (art. 4. 2. TUE). Dicha subordinación implica que los verdaderos fines del Estado son hoy estos últimos (estabilidad de precios, libre competencia..., etc.) y no los fijados por el constituyente. Innecesario resulta recordar que el poder constituyente derivado no ha tomado parte en esta trascendental operación y no lo ha hecho porque no se han activado los procedimientos de reforma constitucional sino que, una vez más, se ha recurrido a la modificación no formal del Texto fundamental, esto es a su mutación. Las consecuencias de todo ello desde el punto de vista del principio democrático son de indudable trascendencia si se tiene en cuenta lo expuesto al inicio de este trabajo.

Con meridiana claridad y evidente acierto, el profesor García Herrera ha señalado como la novedad que se ha producido consiste en la transformación radical de las finalidades de nuestra Constitución: "Si en el Estado Social es admisible, dentro del marco constitucional como limite, la realización de políticas alternativas que modulen la forma de cumplimiento de los fines del art. 9. 2, la normativa europea cancela dicha posibilidad al establecer el marco único de funcionamiento

41 TAJAdura, Javier: El Preámbulo constitucional, ob. cit.

42 TAJADURA, Javier: «La noción de sociedad democrática avanzada en la Constitución española de 1978", en Sistema, núm. 147, 1998. 
y establecer los fines de la Comunidad Europea en términos no coincidentes con los propios de la Constitución. En este sentido es nitida la contradicción entre la estrechez de posibilidades del primado exclusivo de la economía de mercado y de la libre competencia frente al abanico de opciones constitucionales que va desde la economía de mercado del art. $38 \mathrm{CE}$ a la reserva al sector público del art. 128. 2 CE y la programación democrática del art. $131 \mathrm{CE}$ "43.

\section{CONSIDERACIONES FINALES}

Este somero análisis de la crisis del dogma de la supremacía constitucional nos muestra las dos vertientes de la misma. La dimensión formal que se proyecta en las relaciones entre dos ordenamientos con pretensión de primacía, el constitucional y el comunitario, y la dimensión material concretada en una espectacular mutación constitucional consistente en una radical transformación de los fines estatales. Como ha subrayado el profesor García Herrera, es precisamente el análisis de esta segunda vertiente, la sustantiva, el que nos da cuenta de la auténtica dimensión de los efectos del maremoto comunitario que, deben ser, a su vez, incrementados con las consecuencias explosivas de la globalización ${ }^{44}$.

Todo ello determina que los juristas, en general, y los constitucionalistas, en particular, nos encontremos situados en una encrucijada histórica, la determinada por el actual proceso de integración europea y sus consecuencias jurídico-políticas de orden constitucional.

La defensa del principio jurídico de la supremacía constitucional es la lógica consecuencia de la asunción del principio democrático del poder constituyente del pueblo. Ambos principios son inherentes a las Constituciones políticas nacionales y podrían quizás encontrar un día su lugar en una futura Constitución europea que fundara un Estado Constitucional europeo, pero tal cosa está lejos de convertirse en una

43 García Herrera, Miguel Ángel: «Rigidez constitucional...», ob. cit., págs. 80-81.

44 Sobre las repercusiones de la globalización en el Derecho Constitucional, resulta imprescindible: DE VEGA, Pedro: «Mundialización y Derecho Constitucional: la crisis del principio democrático en el constitucionalismo actual'", en Revista de Estudios Políticos, núm. 100, 1998. También resulta de interés, Maestro, Gonzalo: «Globalización y Constitución débil», en Teoría y Realidad Constitucional, n. ${ }^{\circ} 7,2001$. 
realidad, $y$, en este contexto, no puede calificarse sino de suicida la pretensión de renunciar a los instrumentos que pueden garantizar de forma real y efectiva nuestra libertad (las Constituciones de los Estados miembros) en beneficio de unas instituciones supranacionales alejadas de la lógica democrática en la forma de adoptar sus decisiones y cuyos fines últimos no coinciden con los establecidos por el Pueblo español en 1978.

En el contexto descrito, como ha afirmado el profesor García Herrera, en el trabajo antes citado, «resulta indispensable mantener inhiesta la bandera de la Constitución de 1978, sus contenidos sociales, su carácter de norma jurídica suprema, la vigencia de sus procedimientos de reforma y revisión. Al fin y al cabo, su génesis fue el resultado de un proceso constituyente democrático que, con todas sus virtudes e insuficiencias, posibilitó que el pueblo español, como sujeto de soberania, se dotara de una normativa que le dotaba de una unidad política basada en unas opciones que se sintetizan en la fórmula constitucional del Estado Social».

Ahora bien, si esto es así, no menos cierto resulta que el proceso de integración continental es imprescindible para afrontar los desafíos del nuevo siglo. Y nunca se insistirá bastante en que dicho proceso ha garantizado la paz en Europa durante más de medio siglo. Sólo por ello las instituciones comunitarias gozan ya de una legitimidad indiscutible.

Por ello, como ha escrito el profesor Ruipérez «si la Unión Europea tiene que ser que lo sea. Pero que lo sea con los presupuestos del constitucionalismo democrático y social» ${ }^{45}$.

En última instancia, los problemas descritos tienen su raíz en la falta de fundamentación constitucional del proceso de construcción europea. Corregir esa carencia debería ser nuestro principal objetivo. En este sentido el profesor Rubio Llorente, quien a su condición de Catedrático une la de ex-vicepresidente delTribunal Constitucional, ha subrayado como "pese a su carácter indispensable, esta fundamentación constitucional de la integración (comunitaria) es todavía hoy sumamente deficiente, aunque se preste a esa deficiencia muy escasa atención. En su obra admirable de construcción del Derecho Europeo, el Tribunal de Justicia se ha limitado a ignorarla y los teóricos de ese derecho suelen desdeñarla y hasta es frecuente que condenen 
como expresión de un nacionalismo "antieuropeo" las cavilaciones de quienes muestran preocupación por su existencia (...) La conciencia cada vez más extendida de su existencia, las reformas que para corregirla, al menos parcialmente, se han introducido en los últimos años en algunos Estados, y los esfuerzos para dotar a Europa de una "Constitución" (...) son sin embargo la mejor prueba de que tal método ha agotado ya sus posibilidades y de que la creación de la Comunidad Europea como verdadera Rechtsgemeinschaft no puede seguir eludiendo el problema constitucional» 46 .

De seguir eludiéndolo, la distancia entre la normatividad constitucional y la realidad política, que alcanza hoy extremos harto escandalosos, puede acabar siendo insalvable, y erosionar gravemente la credibilidad del sistema y el «sentimiento constitucional».

46 Rubio LLORENTE, F: «El constitucionalismo de los Estados integrados de Europa", en Constituciones de los Estados de la Unión Europea, Ariel, Barcelona, 1997, págs. XVIII-XIX. 